\title{
Empirical Analysis on the Scientific Research Ability of Physical Education Teachers in Research Universities
}

\author{
Yuemin Zhang \\ School of Humanities and Law \\ Northeastern University \\ Shenyang, China \\ School of Physical Education and Health Sciences \\ Yangtze Normal University \\ Chongqing, China
}

\author{
Wanbing Shi \\ School of Humanities and Law \\ Northeastern University \\ Shenyang, China
}

\begin{abstract}
Scientific research ability is an essential quality of university teachers, but also an important index to evaluate research universities. Unfortunately, because of the particularity of the pre-service education, the physical education teachers have a weak foundation in doing scientific research. This article investigates the current situation of physical education teachers' scientific research abilities in research universities using questionnaire survey. Correlation analysis of the physical education teacher's own "attribute" and scientific research ability are performed. It is found that the age and education of physical education teachers in research universities are positively related to their scientific research abilities, while the influences of gender, title, level of foreign language, ability of statistical software application on scientific research ability are weak. Based on the empirical results, this paper proposed some countermeasures to the personnel management and research management of physical education teachers in research universities, and it also can be used to promote scientific research performance of Research University.
\end{abstract}

Keywords-physical education teacher; research university; scientific research ability; empirical analysis

\section{INTRODUCTION}

Since 1998, the construction of research universities in China has been invested a lot of money as an important task of the development of higher education, and has been given strong support from the policy. At this point, the "985 Project" University as a pioneer of the research university has achieved the shift to the focus of scientific research work. In addition, research universities have a liberal research environment, a strong scientific research atmosphere and adequate research funding for teachers to provide a guarantee for scientific research.

Scholars generally believe that teacher's scientific research ability is an important indicator for the evaluation of research universities. And the research university teachers' scientific research ability has been demonstrated in many aspects. It is pointed out that the position and prestige of the university are determined by the quality and quantity of their scientific research, it is reported that the ability of scientific research plays an important role in both the school and the teachers (Ellen Hazelkorn, 2005)[1]. Folk summarizes the importance of management and classification of scientific research ability, and further analyzes the factors that affect the ability of scientific research(Folk, 2010)[2]. It is pointed out that gender, professional title, professional field and nationality have some influence on the relationship between age and research ability [3]. Wanbing Shi et al. explored effective ways to improve the ability of teachers from the scientific research performance evaluation and the relationship between the scientific research ability, and put forward relevant countermeasures[4].

Scientific research ability is an important part of the quality structure of physical education teachers. Both subjective factors and objective factors can affect the ability of scientific research of Physical Education Teachers [5]. Research University provides a relaxed environment for physical education teachers' scientific research activities, where the venue equipment, books and information, network resources are very adequate. However, scientific research ability is the weakness of sports teacher's all along. Ji Xuezheng et al. found that the current sports teachers' ability was not strong, scientific research awareness was weak, lack of scientific innovation[6]. Many scholars have investigated the research ability of teachers from different angles, and they draw the conclusion that the research ability of physical education teachers is not strong, the research environment is poor, and the scientific research awareness needs to be cultivated [7]. However, from the literature review, the research on the relationship between the basic "attribute" of physical education teachers and the scientific research ability of physical education teachers is relatively rare. This study aims to explore the relationship between elements and the elements of influence of PE Teachers' scientific research ability, and put forward the corresponding management strategy from the main factors to proceed PE teachers own development, mainly in view of the research universities physical education teachers: the status quo of academic papers of empirical analysis. The research results will have an important guiding role in 
improving the research ability of the research universities, and it has important reference value for the construction of the sports teaching staff in the research universities.

\section{INTERPRETATION OF THE RELATED CONCEPTS}

\section{A. Physical Education Teachers in Research Universities}

There are a lot of references on research universities. According to the ranking of research universities in terms of Wu Shulian, research universities are the Chinese universities with strong scientific research abilities [8]. The achievement of scientific research cannot be separated from the teachers with high scientific research ability. As a special part of the teachers, physical education teachers in Research University not only have the general character of the research university teachers, but also have the particularity of the physical education teachers. In comparison with the teachers in other subjects, the sports skills of physical education teachers are high, while their foreign language levels and writing skills are slightly inferior. However, compared to the physical education teachers in ordinary colleges and universities, the physical education teachers in research universities have a great advantage such as rich research resources, advanced experimental equipment, good scientific research atmosphere. Therefore, the physical education teachers in Research University should make full use of the existing resources to improve their research abilities.

\section{B. Scientific Research Ability}

Both the ability of scientific research and teaching are the basic quality requirements of the teachers in research universities. Among them, the teaching ability is the display of teachers' ability to use basic knowledge. The ability of scientific research is the research on the frontier knowledge and the ability of scientific research is very important in the research universities. Different scholars analyzed the research ability from different perspectives such as the basis and content of research, the value and role of research ability [9]. Academic paper plays an important role in the evaluation of scientific research ability, especially in the evaluation of sports scientific research ability [10-11]. This paper focuses on the analysis of the relationship between the number of academic papers published in the four years of physical education teachers and the scientific research capacity to conduct an empirical analysis and put forward the countermeasures.

\section{CURRENT SituAtion OF THE RESEARCH AbILITY OF} PHYSICAL EDUCATION TEACHERS IN RESEARCH UNIVERSITIES

The physical education teachers in Research University have outstanding athletic ability, but also needs to have research capabilities. In this paper, the relationship between physical education teachers' scientific research ability and gender, age, professional title, educational background, foreign language proficiency, statistical software usage will be comprehensively analyzed. Through the descriptive analysis and correlation analysis on the influence factors of research university PE Teachers' scientific research ability, the growth law of PE Teachers' scientific research ability will be found and the guideline for sport managers in making scientific research ability evaluation standard will be provided.

\section{A. Data Sources}

In order to make a thorough and comprehensive understanding of the scientific research ability of physical education teachers in Research Universities, in this study, a questionnaire survey was conducted on the teachers of physical education in the public course of the research universities. The distribution principle of the questionnaire is based on regional differences (East, South, West, North, Middle), and the different development orientation of the university. The physical education teachers in five Research Universities were recruited. The sample size of the plan is 150 , and the effective questionnaire number is 123 , the effective rate is $82 \%$. The number of female teachers is 39 , while the number of male teachers is 84. According to academic qualifications, there were 21 doctors, 46 masters, 56 undergraduate, respectively. According to the title, there were 26 professors, 42 associate professors, 48 lecturers, 7 assistants The questionnaire survey involved the problem of the sports teacher's gender, age, title, education and research papers published in the level (CSSCI indexed paper, national quality journal paper, ordinary journal paper), scientific research awards, foreign language proficiency and the use of statistics software.

\section{B. Research Motivations}

Physical education teachers in colleges and universities have a high innovative, creative, and they can achieve higher goal of scientific research on the basis of a certain experience. The growth law of the scientific and technical personnel is positively correlated with age according to the research report on the development of science and technology talent development and research center of Chinese Academy of Sciences.

In order to verify the relationship between age and physical education teachers' scientific research ability, this paper investigated the scientific research ability of teachers at different age stages based on the published scientific papers of teachers at different ages. The following relations will be studied such as the relationship between age and research capacity, the influence of gender, title, education, foreign language proficiency and the use of statistics software and so on.

\section{Data Analysis and Processing}

Statistical software SPSS20.0 was employed in this paper for data analysis. Pearson correlation was used for analyzing the correlation of the statistical data. At present, China's retirement age is 60 years old. The ages from 30 to 60 were divided into four stages: stage 1 (less than 30), stage 2 (31-40), stage 3 (41-50), stage 4 (51-60). In order to normalize the quantification of publish papers, a provincial paper was regarded as one standard and the published papers were weighted. For example, one core paper was normalized as two provincial papers; one EI paper is equivalent to three provincial papers [12]. Through the description of the relationship between sports teachers "properties" and its 
scientific research capability, the sports teacher's gender, age, educational background, professional title, foreign language level and statistical software application ability as independent variables the relationship between PE Teachers' scientific research ability were discussed.

\section{RESULTS AND ANALYSIS}

There are many factors that affect the ability of scientific research of physical education teachers, including external factors and their own factors. The influence factors include the resources, the scientific research environment and the ability of the teaching team. A large number of studies have found that the impact of research institutions on the impact of the researchers is obvious. Professors shifted from the general university to the prestigious universities, his research and output will increase significantly. On the contrary, the results of scientific research will be greatly reduced. The own factors include teachers' qualifications, professional titles, hobbies, etc. Physical education teachers' scientific research ability must be quantified through the scientific, rigorous expert review on innovation and scientificalness. This study examine the main effect of the physical education teachers' self attributes of research universities in China based on the academic papers published by research universities in China as the scale of sports teachers' scientific research ability.

\section{A. Descriptive Analysis of the Relationship between Age, Gender and Research Ability of Physical Education Teachers in Research Universities}

Teacher's age, to a certain extent, reflects not only the ability of scientific research and innovation, but also the experience of teachers' scientific research and teaching. To achieve the stability, complementarily and rationality of the construction of scientific research team of physical education teachers, the composition of different age and gender can be optimized through the statistical analysis of the whole sports teachers' age, gender and other scientific research. The statistical results of the survey of the different age and gender groups of the PE teachers in research universities were demonstrated in "Fig. 1" and Fig.2".

As shown in "Fig. 1", the amount of papers published by young PE teachers peaked at 30 years old. There are many reasons. Firstly, the young teachers are more active in thinking and have a passion for exploring the frontiers of knowledge. Secondly, most of them have just completed a master's or doctoral studies. These young teachers have advantages in research and some of their achieved results during their graduate studies will be published in the next few years. Thirdly, the talent introduction policies of universities promoted the enthusiasm of young teachers. Fourthly, the old professor's role models have a great driving effect on young teachers when they came to research universities.

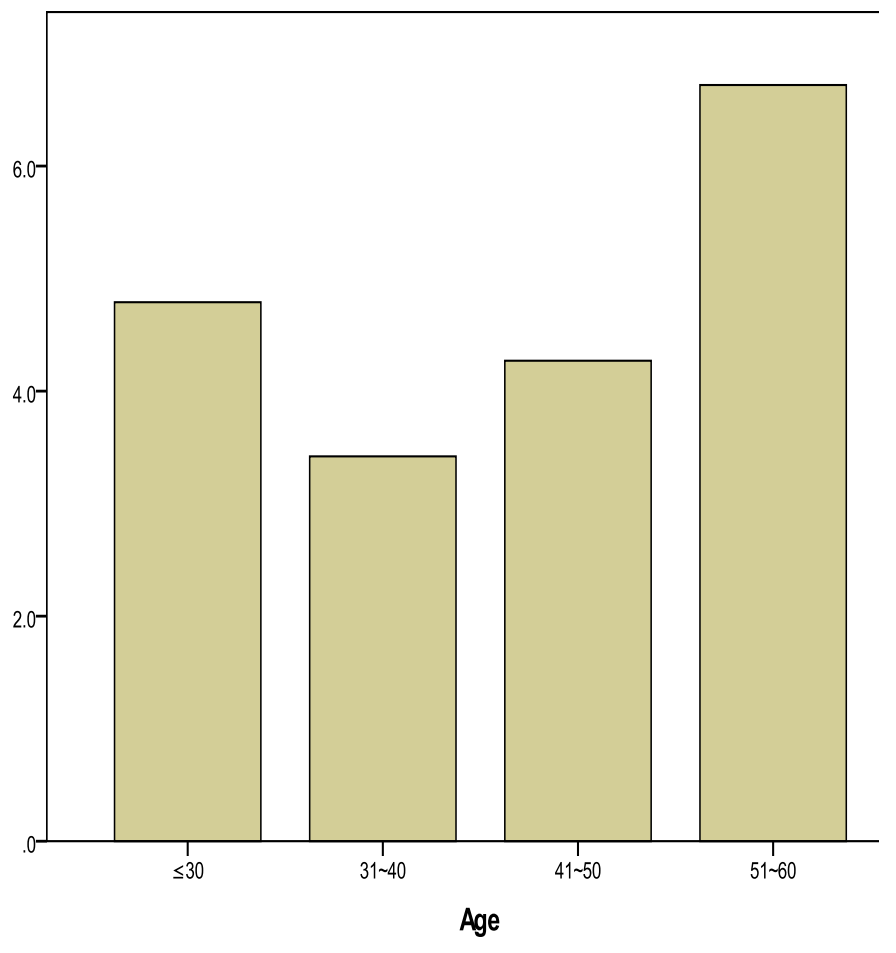

Fig. 1. Averaged number of annual papers published by physical education teachers in Research Universities.

At 31-40 years old age, the teachers can get a series of national policy support. For example, the humanities and social research youth fund project of Ministry of Education and so on can have incentive effect to these teachers. However, the number of sports teachers in this age group has been declined. The first possible reason is physical education teachers at this age stage faced with the heavy teaching work, and there is not much time for scientific research. The second possible reason is this age group of teachers has a large family pressure of marriage, children, buy a house, etc. The third possible reason is that this age group of teachers is in the initial stage of research, and the university's training and learning opportunities are less.

Physical education teachers at the age between $41-50$ years old are the most valuable talent resources. Most of them have deputy senior and above titles. They are full of experience in teaching and research. Because of the specialty of physical education, many teachers think it is difficult to achieve the requirements of the promotion through the efforts. They give up their chances for promotions and then their published papers become less.

Whether male or female PE teachers between 51-60 years of age, their published papers have a larger rise. This age of physical education teachers generally have a professor title, and they have the strong ability to carry out scientific research. Colleges and universities should pay more attention and humanistic care to the teaching, scientific research and living conditions of the teachers in this age group, and to encourage them to achieve more high quality outputs of scientific research. 
From "Fig. 2" we can find that male teachers published more papers than the female teachers. It is due to female teachers are mostly in the growth period. However, with the increase of age, the differences in the amount of published papers between male and female teachers gradually reduced.

Before the age of 30 , the average output value of male PE teachers is higher, reaching an average of about 6.5 per person per year. The possible reason is that young male PE teachers have higher education background, and they have the ability to carry out scientific research. In the age of 31-50 years old, male and female PE Teachers' scientific research output showed a downward trend. However, at the age of 51-60 years' old, male and female teachers of the papers published increased. At this stage, the burden on the family of teachers is small, and the scientific research experience is rich.

Middle aged teachers are the backbone of teachers. The decline of the papers published by middle aged teachers should lead to more attention. Male PE teacher published a number of papers each year less than 4 , and female PE teachers published 2 papers per year. For the PE teachers in Research University, this number only can guarantee their annual research workload requirements. At the same time, it can be seen that the teachers of this age group has been influenced by some objective reasons such as too heavy teaching task and bigger family burden.

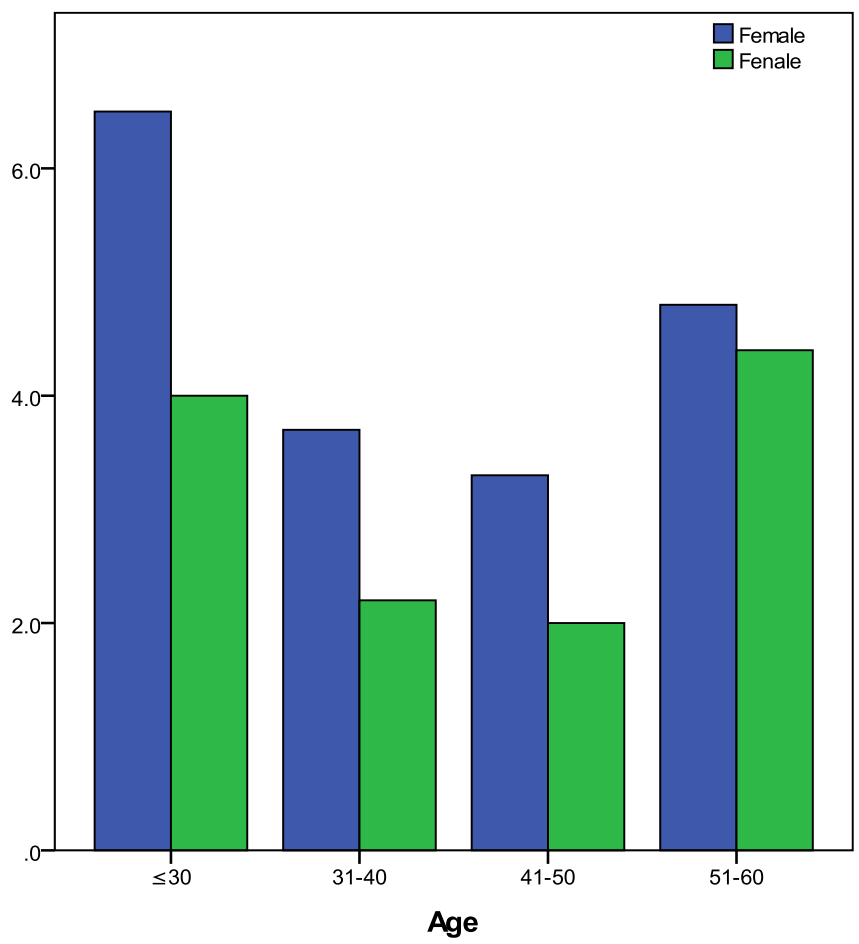

Fig. 2. Average number of annual papers published by male and female physical education teachers in Research University at different age stages.

\section{B. Descriptive Analysis of the Relationship between Physical Education Teachers' Academic Qualifications, Professional Title and Research Ability in Research Universities}

In addition to age, gender, education, professional title is one of the main factors that affect the ability of scientific research. From "Fig. 3", it is notable that the degree of education and scientific research ability is related.

"Fig. 3" describes the relationship between different age groups and different academic qualifications of research university sports teachers. It is notable that physical education teachers' papers published increased with the increasing degree of education. Especially before the age of 30, the doctoral education of young teachers published significantly more than the master's degree, bachelor's degree in Physical Education teachers. Average annual publication of papers is 9 papers. During the 31-40 years of age, doctoral degree of physical education teachers are the main body of the teachers. Their output of the paper increased significantly. The publication of the teachers with undergraduate education continued to increase with age. Research university sports teachers mainly have master or doctoral degrees. Overall, the quality of the papers published by PE teachers is not high. Overall, the quality of the papers published by PE teachers with bachelor degree is not high. Due to their relatively low academic qualifications and the school education system is not perfect, these teachers are lack of scientific research abilities.

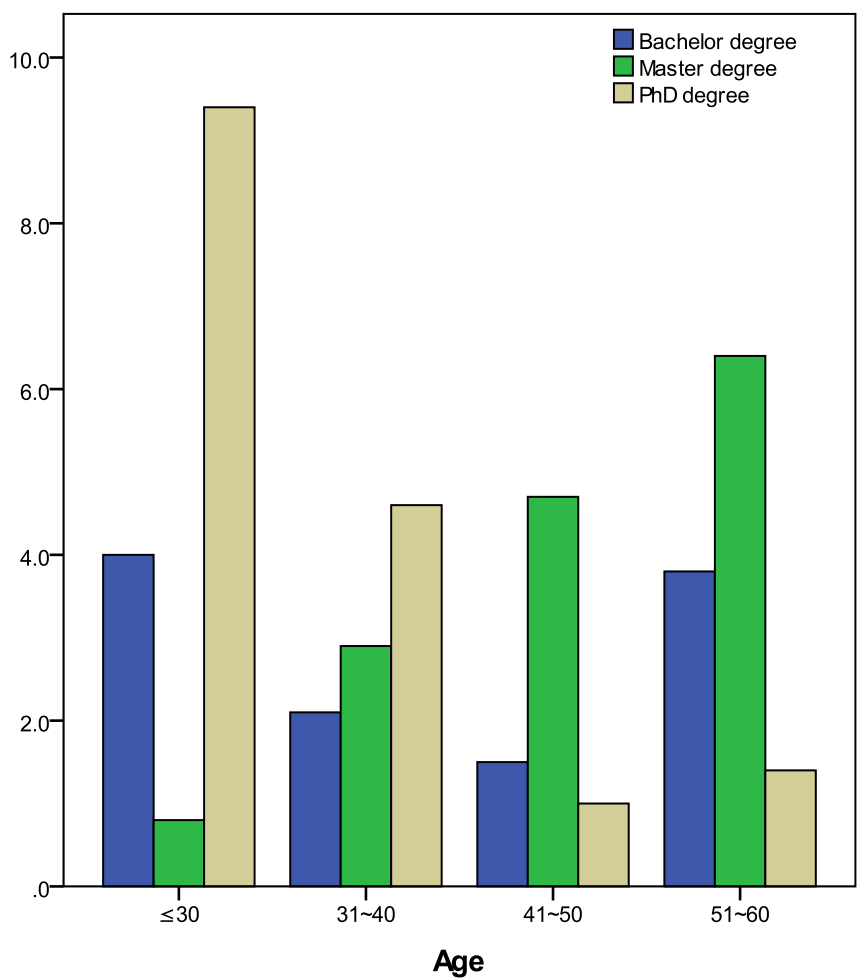

Fig. 3. Average number of annual papers published by physical education teachers in Research University at different age stages with different educations 
The physical education teachers with master degree are the core group of physical education teachers. Whether it is teaching or scientific research has an important responsibility and mission. Due to the requirements of the new teachers must have a master's degree or above, so the core group of the physical education teachers should develop the objective environment for their scientific research ability.

The physical education teachers with doctoral degree have fruitful research outputs, especially for the young teachers with doctor degree. In China, the recruit of PhD student in physical education is relatively late and the quota for recruiting $\mathrm{PhD}$ student in physical education is less too. More physical education teachers with doctoral degree still need to be recruited.

Title Structure is an important symbol to evaluate the quality and effectiveness of physical education teachers' scientific research team. If the influence factors of the professional title structure of the research university on the scientific research ability were analyzed, and the reasons were found out, the scientific research ability of physical education teachers will be promoted greatly.

"Fig. 4" shows the averaged number of annual papers published by the teachers of physical education in Research Universities. It is notable that lecturers, associate professors and professors are the main body of scientific research output in research universities, while the teacher assistants published less paper. Even some teacher assistants at the age less than 30 still didn't publish any paper.

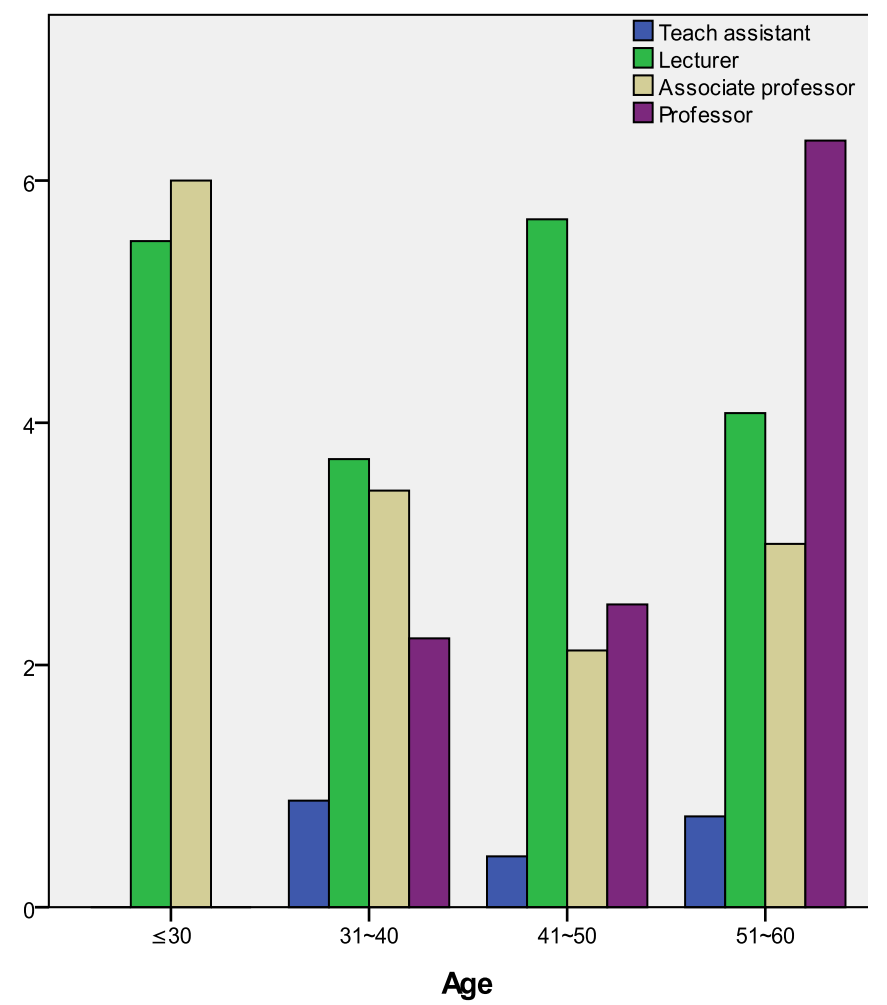

Fig. 4. Average number of annual papers published by physical education teachers in research university at different age stages with different professional titles.
Among the physical education teachers at the age between 31 and 40 years, lecturers and associate professors are the main body, and the number of professors is relatively small. As the age increases the amount of published papers continues to rise. Especially for the professors at the age 51-60 years, they published more papers than those in the previous two age stages (31-40 years and 41-50 years).

With the increase of age, the number and the quality of the scientific papers published by professors are on the rise. The research output of the associate professor in physical education department decline with the growth of age. This group is influenced greatly due to family stress and the relatively high requirement for promotion.

\section{Descriptive Analysis of the Relationship between the} Ability of Using Statistical Software, the Level of Foreign Language and the Ability of Scientific Research

The use of foreign language proficiency and statistical software has become an indispensable tool for the research of physical education teachers in research universities. The impact of these factors on the research ability of physical education teachers in Research University is demonstrated in "Fig. 5" and "Fig. 6".

In the information age, the advanced modern technologies are the important tools for high quality scientific research.

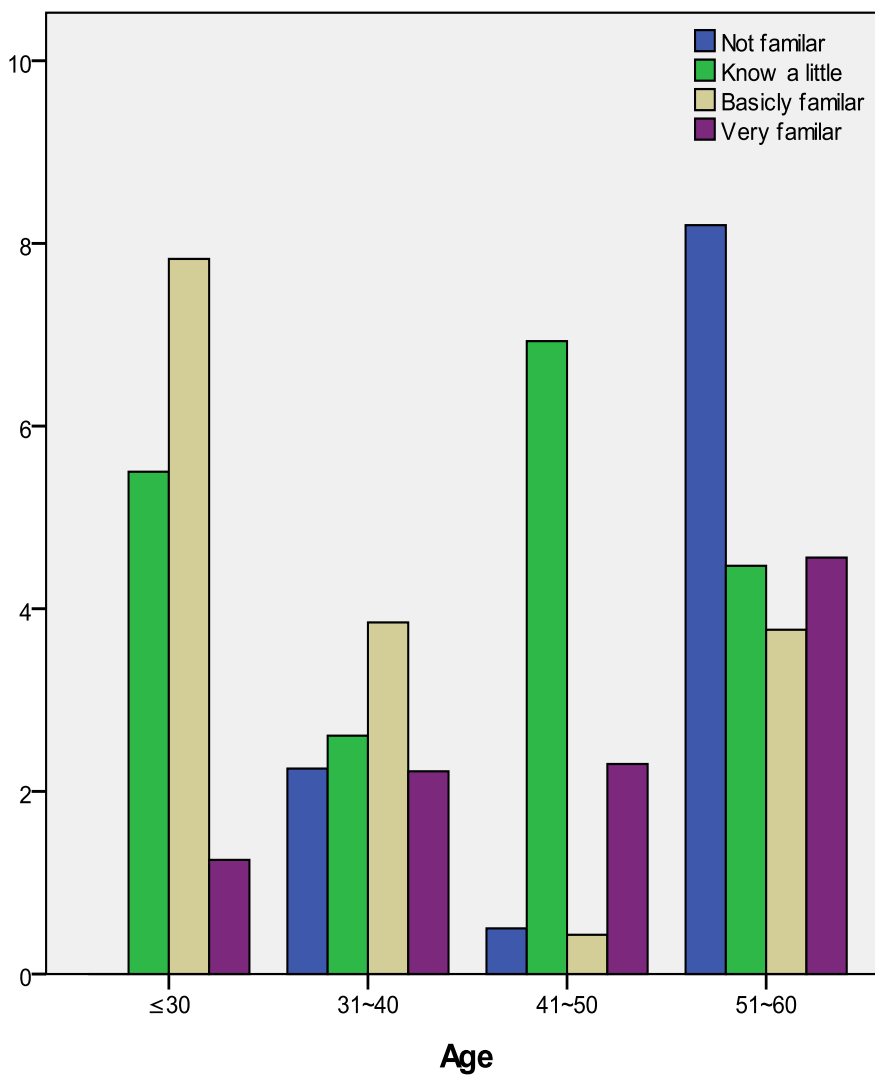

Fig. 5. Average number of annual papers published by physical education teachers in research university at different age stages with different levels of using statistics software. 
From "Fig. 5" we can find that the teachers who are familiar with statistical software published the most papers, while the teachers who are familiar with statistical software published the least papers. A lot of physical education teachers published papers on teaching because of their of writing ability, foreign language level are not high enough. Based on lots of statistical analysis, the ability of using statistical software can help physical education teachers in the paper publication.

"Fig. 6" illustrates the relationship between the level of foreign language proficiency and the number of papers published by research university PE teachers. From Fig. 6, we can find that the teachers who are familiar with English language publish the most papers among all the investigated teachers. The averaged number of annual publication is 12.5 papers. That is to say English is an effective tool for research in physical education.

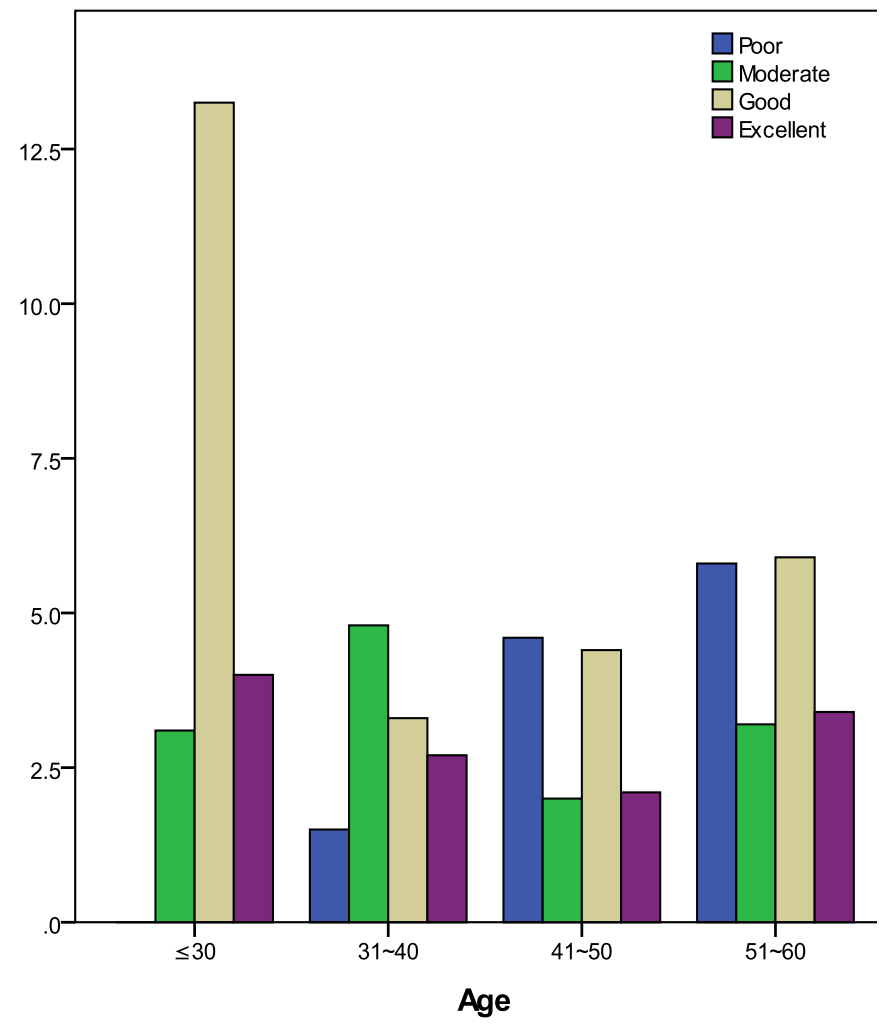

Fig. 6. The relationship between the foreign language proficiency of the sports teachers in the research universities and the number of papers published annually.

\section{Correlation Analysis of Scientific Research Ability and Restriction Factor}

Having analyzed the construction of the physical education teachers' team, we can find that the above factors do influence the research ability of PE teacher at different extents [13]. The results of the correlation analysis of these factors are listed in "Table I".
TABLE I. CORRELATION ANALYSIS OF SCIENTIFIC RESEARCH ABILITY AND RESTRICTION FACTOR

\begin{tabular}{|l|l|l|}
\hline \multicolumn{1}{|c|}{ Factors } & Correlation & \multicolumn{1}{c|}{ Significance } \\
\hline Gender & -0.135 & 0.51 \\
\hline Age & 0.267 & $0.003^{*}$ \\
\hline Education & 0.184 & $0.04^{*}$ \\
\hline professional ranks and titles & 0.070 & 0.89 \\
\hline English level & 0.064 & 0.99 \\
\hline Ability of using statistical software & -0.122 & 0.18 \\
\hline
\end{tabular}

It is notable from "Table I" that both age and education have significantly influence on the number of the published paper. Furthermore, the factors such as gender, professional title, and level of English language have less influence on the number of the published paper. According to Pearson correlation coefficient, the factor such as age, education, professional title and level of English language are positive correlated with the scientific research ability of PE teacher. That is to say, the ability of scientific research increases with the age and professional title. Gender and the ability of using statistical software have less influence on the ability of scientific research.

\section{CONCLUSION}

The statistical analysis demonstrated that age and education are significant correlated with the scientific research ability of PE teacher, while gender, professional title and level of English language, and the ability of using statistical software have less influence on the ability of scientific research. The group with strongest scientific research ability are the PE professors who have $\mathrm{PhD}$ degree and are familiar with English and statistical software. Therefore, the physical education teachers with high professional title, doctoral degree are the focus of the construction of teaching staff.

In the face of the complex and dynamic relationship between the factors which restrict and influence the scientific research ability of the teachers based on the above conclusion of empirical research, this study puts forward the following countermeasures and suggestions to improve the management of physical education teachers in research universities.

\section{A. Pay More Attention to the Recruitment and Training of PE Teachers}

The teachers in Research University attach great importance to scientific research. Because of the particularity of the teaching work of PE teachers, many universities pay more attention to the special technical level of sports during the recruitment of PE teachers and they pay less attention to the scientific research ability of PE teachers. As the entrance to the recruitment of personnel, personnel department need to investigate the research ability of PE teachers (such as education, level of English language, ability of using statistical software) under the premise of meeting the teaching requirements. Therefore, in the recruitment of physical education teachers should be consistent with the educational objectives of the research university. Young teachers' scientific research ability is the key for overall promotion of the scientific research level of PE team. 


\section{B. Take Effective Measures to Strengthen the Scientific Research Consciousness of PE Teachers}

Research University provides a superior scientific research platform for the development of physical education teachers, creating a relaxed atmosphere of scientific research. Physical education teachers should make full use of the existing resources, and actively play a subjective initiative to carry out scientific research and exploration. They need to overcome the burden of the family and the temptation of modern society. Furthermore, scientific research is a creative business rather than a boring one. Scientific research interests need to be cultivated consciously. PE teachers need to participate in a variety of academic seminars and try to grasp the research trends in related field and promote scientific research accomplishment.

In view of the fact that the research foundation of physical education teachers is weak, the teachers' scientific research standard of the research university, is a guide for the PE teachers to improve their abilities of using foreign language and statistics software, and to master the necessary skills to carry out scientific research. Furthermore, they should combine their existing research foundations, expand their research fields. In particular, they need to make full use of the advantages of research universities and other related disciplines of comprehensive universities. Finally, PE teachers can set up a good sense of scientific research and reverse the overall situation of the weak scientific research.

\section{Strengthen the Training of PE Teachers}

From the result of this paper we can find that the vocational training of $\mathrm{PE}$ teachers in Research University of cannot meet the needs of PE teachers. It should be established for different training courses, to meet the needs of PE teachers to improve their abilities of scientific research. At the same time, the incentive mechanism for different ages of PE teachers needs to be established. The enthusiasm of sports teachers need to be fully mobilized to carry out scientific research to enhance the overall level of PE teachers.

\section{Stimulate The Enthusiasm of PE Teachers Through the Development of Scientific Research Incentive Policies}

As a direct leadership of teachers' scientific research management, the department of science and technology needs to unify and normalize the manage regardless of the declaration of the subject, the management of scientific research funds, the convening of the meeting of scientific research, and so on. Currently, a lot of university scientific research reward policy standards for sports teachers are relatively high. It should be aimed at the physical education teacher's scientific research practice, formulate the scientific research management mechanism suitable for the PE teachers. At the same time, PE teachers should be encouraged to participate in academic exchange meetings, to give support in terms of funding, so that the teachers can grasp the forefront of the related fields and then the overall abilities of the PE teachers' research team can be promoted greatly.

\section{E. Pay Attention to the Physical Education Teachers' Scientific Research Performance Evaluation}

As an important measure to measure the scientific research ability of PE teachers, performance evaluation has an important influence on the enthusiasm of PE teachers' scientific research ability. The whole teachers in the research universities have higher research level of the, while the research university physical education teachers are the special people who are relatively weak in the scientific research foundation. We should follow the law of physical education teachers' growth, in order to mobilize the enthusiasm of sports teachers' scientific research, to achieve the desired results of scientific research management. From the results of this study we can find that all the PE teachers in different stages have a great improvement in the research capacity. We need to make a scientific and reasonable performance evaluation system for the long-term development of PE teachers on the basis of drawing lessons from the experience of advanced teachers' performance evaluation in foreign universities.

In short, Research University needs to create a sound scientific research environment for the PE teachers with scientific research potential through the introduction of school personnel system, teacher training system, research incentives, scientific research incentives and other means. For PE teachers with different levels of scientific research, we should take targeted means to increase the opportunity to train teachers. The performance evaluation of PE teachers need to be attached in order to improve the overall level of scientific research of PE teachers. Therefore, a healthy research team will be formed.

\section{ACKNOWLEDGMENT}

This work is supported by the humanities and social sciences research program of the Ministry of Education "Research on the theory and method of improving the performance of University Teachers"(No. 13YJA880064) and National Social Science Foundation Project "Research on the performance evaluation system of the humanities and social sciences teachers in Colleges and Universities" (No. BFA150043).

\section{REFERENCES}

[1] Hazelkorn E., University Research Management: Developing Research in New Institutions[M]. Dublin, OECD Publishing, 2005.

[2] Schützenmeister F., University research management: an exploratory literature review $[\mathrm{J}]$. Institute of European Studies UC Berkeley, 2010(2):1-32.

[3] Zeng Lin, The setting sun is infinitely good - the relationship between the age and the scientific research ability is published by the professor from the American University[J] , Peking University Education Review, 2009(1):113. (In Chinese).

[4] Wanbing Shi, Hui Yang, Research on the methods of performance evaluation of teachers' scientific research in colleges and universities, Higher Education Exploration, 2014(6):112-117. (In Chinese).

[5] Zhang Guosheng, Research on status of PE teachers in private universities, Informatics and Management Science V, The Series Lecture Notes in Electrical Engineering[J], 2012, 208: 537-544.

[6] Xuezheng $\mathrm{Ji}$, Investigation and research on the current situation of College Physical Education Teachers' scientific research ability in 
[7] Tianjin[J]. Contemporary Sports Technology, 2014(27):73-75. (In Chinese).

[8] Fang Chen, The cultivation of scientific research ability of young college young teachers [J]. Fight - Sports Forum, No. 1: 16-17, 2012.

[9] Shulian WU, Jia Lv, et al. 2009 China University Evaluation [J]. Assessment of higher education in China, 2009.1,22-25.

[10] Wenli Xie, Research on current situation and countermeasures of physical education teachers in Colleges and universities in Jiangxi Province[D], Nanchang University, 2010.12. (In Chinese).

[11] Lin Zeng, Age and scientific research ability: report from a professor of four year university in the United States[J], Scientific Research, 2009(8):1157-1163. (In Chinese).

[12] Kejun Wang, The evaluation system of University Teachers' performance in the United States and its enlightenment to China[J], Journal of Northeastern University (Social science edition), 2013, 15(6):642-646. (In Chinese).

[13] Yulong Ma, Yanjun Zhao, Analysis on quantitative standard of physical education teachers' professional title evaluation in Daqing Petroleum Institute[J]. Teachers Journal, 2009(1):112. (In Chinese).

[14] Tan Lei, Xintian Zhuang, Peng Han, Research on the comprehensive evaluation method of university talents' scientific research ability based on data mining [J], Journal of Northeastern University (Social science edition), 2014,16(6):596-600. (In Chinese). 